\title{
Relevansi Kompetensi Lulusan Politeknik Negeri Balikpapan terhadap Model Kompetensi Utama Dudi (Dunia Usaha dan Dunia Industri)
}

\author{
Elisabeth Milaningrum ${ }^{1 *}$, Patria Rahmawaty ${ }^{2}$ \\ 1,2 Politeknik Negeri Balikpapan \\ *Email:elisabeth.milaningrum@poltekba.ac.id
}

\begin{abstract}
The higher vocational education must be oriented with bussines world and insdustry's need. The aim of this research is to identify the relevance of Balikpapan State Polytechnic graduates to the main competence of bussines world and insdustry. This study focussed with the relevance beetwen the result of tracer study and user survey to stakeholder. The subject of this research is Balikpapan State Polytechnic graduates. The sampling methode use snowball sampling. The technique of collecting data used questionare and dokumentation, however techniques for analizing data used descriptive analisyst. Based on the result of tracer study, it can be concluded that the graduates comptenece profile have close horizontal relevance ( the relevance between graduate competence and field work) and for vertical relevance ( the relevance beetwen level education and the qualification eduactaion of the job) is high enough. However, based on the result of user survey, it was found mismatch between Balikpapan State Polytechnic graduates that was not suitable with the stakeholder's need in both aspect either hard skill that consist of : the field of scince, foerign language ability, and the ability of information technology, while for soft skill comptenece that consists of communication skill, team work, dan self development.Therefore, Balikpapan State Polytecnich institusion need to improve the conptenece of gradutaes either hard skill or soft skill based on the staholders' need.
\end{abstract}

Keywords: Relevance, Competence, Graduates, Tracer Study, User Survey, Business World and Industry

\begin{abstract}
Abstrak
Pendidikan tinggi vokasi harus berorientasi pada kompetensi yang dibutuhkan oleh dunia usaha dan industri (DUDI). Penelitian ini bertujuan untuk mengkaji tingkat relevansi (kesesuaian) lulusan Poltekba terhadap model kompetensi yang dibutuhkan oleh DUDI. Kajian diarahkan pada keselarasan antara hasil tracer study dan user survey terhadap DUDI pengguna lulusan Poltekba. Penelitian ini mengambil subjek alumni Poltekba. Teknik sampling yang digunakan adalah snowball sampling. Teknik pengumpulan data menggunakan kuesioner dan dokumentasi sedangkan teknik analisis data menggunakan analisis deskriptif. Berdasarkan hasil tracer study dapat disimpulkan bahwa profil kompetensi lulusan memiliki tingkat keselarasan horizontal (keselarasaan bidang pekerjaan alumni dengan bidang ilmu) yang erat dan tingkat keselarasan vertikal (keselarasan antara jenjang pendidikan dengan jenjang kualifikasi pekerjaan) yang cukup tinggi. Akan tetapi berdasarkan hasil user survey ditemukan mismatch antara kompetensi lulusan Poltekba yang belum sesuai dengan model kompetensi utama yang dibutuhkan DUDI yakni dalam aspek hardskill yang meliputi keahlian pada bidang ilmu, kemampuan berbahasa asing, dan penggunaan teknologi informasi, sedangkan kemampuan soft skill yang meliputi kemampuan berkomunikasi, kerjasama, dan pengembangan diri. Oleha karena itu institusi Poltekba perlu melakukan peningkatan kualitas kompetensi lulusan baik hard skill maupun soft skill seusai dengan kebutuhan DUDI.
\end{abstract}

Kata kunci: Relevansi, Kompetensi, Lulusan, Tracer Study, User Survey, DUDI. 


\section{Pendahuluan}

Pendidikan tinggi vokasi merupakan pendidikan tinggi yang mengarahkan mahasiswa untuk mengembangkan keahlian terapan, beradaptasi pada bidang pekerjaan tertentu dan dapat menciptakan peluang kerja. Menurut Prasetyono (2017), pendidikan tinggi vokasi berorientasi pada kecakapan kerja sesuai dengan perkembangan ilmu pengetahuan dan teknologi terapan. Salah satu faktor keberhasilan pendidikan tinggi vokasi adalah aspek relevansi. Relevansi merupakan komponen penting karena merupakan faktor yang menentukan eksistensi dari suatu lembaga pendidikan.

Menurut Muhson (2012), terdapat tiga aspek perguruan tinggi yang saling berkaitan dan memiliki konstribusi langsung terhadap peningkatan daya saing sumber daya manusia yakni kualitas, relevansi, dan kompetensi. Salah satu bentuk penguatan terhadap perkembangan DUDI pada ekonomi digital dan revolusi industri 4.0 saat ini yakni menghasilkan kompetensi lulusan yang handal dan sesuai dengan kebutuhan industri. Kompetensi tenaga kerja yang dibutuhkan DUDI dapat mengalami perubahan seiiring berjalannya waktu dan perkembangan zaman, contohnya berdasarkan data pada CDC Poltekba, di Indonesia dan khususnya di area Kalimantan Timur sendiri yang merupakan kota tambang minyak, hingga tahun 2014 kebutuhan tenaga ahli dibidang perminyakan masih sangat besar. Namun memasuki tahun 2015, kebutuhan tenaga ahli di bidang perminyakan cenderung berkurang bahkan hingga tahun 2018 menunjukan penurunan yang tajam dan pada tahun 2019 baru terlihat progress kenaikan permintaan tenaga ahli di bidang perminyakan dimana beberapa perusahaan migas baik nasional maupun multinasional sudah mulai membuka perekrutan bagi tenaga kerja ahli maupun fresh graduate.

Gaeta, Lavadera, \& Pastore (2017), menyatakan bahwa pendidikan bertujuan untuk menciptakan output yang terbaik dan menghasilkan outcome yang dapat berdampak positif bagi kepentingan pendidikan dan organisasi tersebut. Salah satu tujuan pendidikan tinggi vokasi adalah tempat untuk menyediakan tenaga kerja yang terampil, ahli, dan memiliki skill yang terbaik, sedangkan kewajiban para stakeholder adalah bagaimana membantu sistem pendidikan sesuai dengan kebutuhan industri dan kebutuhan masyarakat demi mengurangi tingkat pengangguran dari lulusan pendidikan tinggi vokasi yang telah dipaparkan sebelumnya. Sedangkan DUDI (Dunia Usaha dan Dunia Industri) berkembang pesat setiap waktu, selalu didesak untuk dapat memenuhi kebutuhan masyarakat, sehingga antara pendidikan tinggi vokasi yang menciptakan lulusan yang berkompeten memiliki keterkaitan dengan dunia industri yang memerlukan sumber daya manusia yang handal demi memenuhi kebutuhan hidup masayarakat sehingga dibutuhkan link and match antara dunia pendidikan tinggi vokasi dan DUDI.Peserta didik menghadiri pendidikan di kampus dan memilih bidang gelar dengan harapan berhasil di dalam dunia kerja. Menurut Robst (2017), salah satu aspek keberhasilan pasar kerja adalah kemampuan untuk memanfaatkan investasi apa yang didapat di sekolah dalam pekerjaan di masa depan. The quantity of schooling is only one way to consider the match between schooling and jobs. Selalin itu, Sloane (2013), menyatakan bahwa workers may be mismatched if the level of schooling is appropriate but the type of schooling is not.

Menurut Boudarbat \& Chernoff (2015), banyak terdapat penelitian yang berkaitan dengan banyaknya fenomena ketidak mampuan pekerjaan melihat tingkat pendidikan. Saat seseorang bekerja dalam posisi di bawah tingkat studi seseorang, keterampilan yang dipelajari dalam pendidikan formal mungkin tidak sepenuhnya digunakan. Missmatch pendidikan terjadi secara vertikal yaitu antara tingkat pendidikan dan kebutuhan pekerjaan dan terjadi secara horizontal dimana terjadinya ketidakcocokan bidang studi yang diteliti dengan pekerjaan. Menurut Hersch (2012), menyatakan bahwa bidang studi yang dipelajari penting karena memungkinkan untuk menganalisis berbagai jenis keterampilan. Pendidikan tidak hanya menyediakan modal manusia secara umum, namun bidang studi tertentu memberikan 
ketrampilan spesifik pekerjaan untuk pasar kerja.

Menurut Senarath, \& Patabendige (2014), private sector business leaders believe that this mismatch is primarily due to the problems of educational structure, quality and the content of the educational system, particularly university system has failed to provide the required skills, aptitudes, and job orientation for the graduate workforce. Ini dengan jelas menjelaskan bahwa education missmatch adalah masalah sisi penawaran tenaga kerja. Selain mengidentifikasi alasan education missmatch, penting untuk mengidentifikasi dampak lulusan yang tidak sesuai dengan pendidikan, bahkan banyaknya education mismatch menjadikan pengangguran semakin meningkat. Hal ini juga merupakan tantangan besar yang harus dihadapi pemerintah Indonesia dalam upaya menciptakan tenaga kerja terampil sesuai dengan kompetensi yang dibutuhkan oleh dunia kerja, dalam hal ini adalah dunia usaha/dunia industri (DUDI) yang relevansinya menyangkut dua dimensi, yaitu sekolah dan dunia kerja atau masyarakat.

Berdasarkan laporan World Economic Forum (2018), mencatat, dalam lima tahun terakhir banyak jenis pekerjaan yang hilang, tapi bermunculan jenis-jenis pekerjaan baru yang memerlukan keahlian tinggi dan keterampilan khusus, sejalan dengan perubahan peta ketenagakerjaan dan tren pergeseran a new human-machine frontier within existing work tasks. Pada 2018, rata-rata $71 \%$ suatu jenis pekerjaan di industri dijalankan manusia dan hanya $29 \%$ yang dioperasikan mesin. Sedangkan pada tahun 2022 nanti, diprediksi suatu pekerjaan yang bertumpu pada manusia diperkirakan akan menurun tajam menjadi 58\% akibat otomasi, sedangkan pekerjaan yang bertumpu pada mesin akan meningkat signifikan menjadi $42 \%$. Di era industri $4.0 \mathrm{ini}$, pekerjaan yang mengandalkan mesin dan algoritme akan semakin dominan. Oleh karena itu, Poltekba harus dapat membangun link and match dengan DUDI agar dapat mempersiapkan kompetensi calon lulusan yang update akan perkembangan teknologi dan ilmu pengetahuan yang sedang diterapkan pada DUDI. Dalam upaya membangun relasi link and match dengan DUDI untuk mengetahui perkembangan model kompetensi utama yang dibutuhkan DUDI maka dilakukan user survey terhadap pengguna lulusan Poltekba, sedangkan untuk mengetahui seberapa besar lulusan Poltekba dapat mampu berkiprah pada DUDI sesuai relevansi pendidikannya maka dilakukan upaya penelusuran terhadap lulusannya (tracer study).

Adapun pentingnya perlu mengetahui relevansi kompetensi lulusan Poltekba dengan DUDI yakni: (1) Pentingnya mengetahui kualitas profil kompetensi lulusan Poltekba terhadap model kompetensi utama DUDI sebagai evaluator institusi dalam penyempurnaan kualitas proses pembelajaran, pengembangan kurikulum dan penciptaan budaya kampus, (2) Pentingnya mengetahui tingkat kepuasaan pengguna lulusan (DUDI) terhadap outcome dan output lulusan Poltekba sebagai acuan dalam membuat rancangan program dan kegiatan di masa yang akan datang guna menunjang peningkatan kompetensi baik hard skill maupun soft skill, (3) Pentingnya mengubah paradigma orientasi pendidikan dari supply minded menjadi demand minded sehingga dapat meningkatkan daya serap lulusan pada DUDI. (4) Adanya ketidaksesuaian (missmatch) kompetensi yang dimiliki lulusan Poltekba dengan kebutuhan DUDI khususnya pada kemampuan soft skill dimana pada lulusan generasi milenial ini mengalami penurunan kualitas yang cenderung hanya mengedepankan hard skill saja. (5) Pentingnya upaya untuk mempersingkat masa tunggu lulusan mendapatkan pekerjaan sesuai dengan bidang keahlian dan kualifikasi pendidikannya. Untuk itu, penelitian ini bertujuan untuk: (1) mendeskripsikan profil kompetensi lulusan Poltekba berdasarkan hasil tracer study, (2) mendeskripsikan model kompetensi yang dibutuhkan DUDI berdasarkan hasil user survey Poltekba, (3) mengklasifikasikan tingkat relevansi antara kompetensi lulusan Poltekba dengan model kompetensi utama yang dibutuhkan DUDI dalam meningkatkan daya serap lulusan pada DUDI. 


\section{Metodologi}

Penelitian menggunakan penelitian deskriptif eksploratif. Sumber data yang digunakan dalam penelitian ini adalah data primer dan data sekunder. Data primer yang digunakan dalam penelitian ini berasal dari survey dan wawancara dengan menyebarkan kuesioner tracer study kepada alumni serta kuesioner user survey terhadap pengguna lulusan poltekba secara online. Instrumen kuesioner tracer study dibuat sesuai dengan panduan tracer study online Belmawa dan instrument tambahan sesuai dengan karakteristik kebutuhan Poltekba. Kegiatan pengisian kuesioner tracer study dilakukan secara online dengan 27 kategori penilaian baik hard skill maupun softskill. Adapan lulusan yang di trace yakni lulusan tahun 2019 pada program studi Tekni Mesin (TM), Teknik Elektronika (TE), Teknik Sipil (TS), dana Tata Boga (TB). Sedangkan data sekunder yang digunakan dalam penelitian ini diantaranya data tentang data alumni, penelitian terdahulu, dan jurnal.

Variabel yang diteliti dalam penelitian ini meliputi tingkat relevansi lulusan yakni tingkat kesesuaian bidang pekerjaan yang diperoleh lulusan, tingkat pendidikan dengan kualifikasi pekerjaan lulusan, dan tingkat kepuasaan pengguna lulusan Poltekba. Instrumen yang digunakan untuk mengukur tingkat kesesuaian bidang pekerjaan yang diperoleh lulusan dan tingkat pendidikan dengan kualifikasi pekerjaan lulusan menggunakan intrumen pertanyaan yang terdapat pada kuesioner tracer study dimana untuk kesesuaian bidang pekerjaan dikalsifikasikan menjadi 3 kategori yakni sangat erat, erat dan tidak erat, sedangkan intrumen pertanyaan yang digunakan untuk mengukur tingkat pendidikan dengan kualifikasi pekerjaan lulusan diklasifikasikan menjadi 4 kategori yakni tingkat lebih tinggi, tingkat yang sama, tingkat lebih rendah, dan tidak perlu pendidikan. Instrumen yang digunakan untuk mengukur tingkat kepuasaan pengguna lulusan Poltekba menggunakan instrument kuesioner user survey dimana tedapat 7 aspek pertanyaan yang yang meliputi etika, keahlian pada bidang ilmu, kemampuan berbahasa asing, penggunaan teknologi informasi, kemampuan berkomunikasi, kerjasama, serta pengembangan diri dimana diklasifikasikan dalam 4 kategori yakni sangat baik, baik, cukup, dan kurang.

Relevansi kompetensi lulusan Poltekba dalam DUDI dapat dilihat dari populasi dalam penelitian ini yakni seluruh lulusan (alumni) Politeknik Negeri Balikpapan tahun 2019. Sedangkan sampel diambil secara snowball sampling dengan memanfaatkan database alumni dari CDC Poltekba tentang keberadaan alumni dan kerjasama DUDI. Dalam penelitian ini teknik analisis data yang digunakan adalah dengan menggunakan analisis data statistik deskriptif, yakni berupa frekuensi, persentase, dan rata - rata dengan cara mengklasifikasikan data. Tahapan yang dilakukan dalam menganalisis data penelitian survei mengikuti Masri, Singarimbun (1989), meliputi: (1) memasukkan data ke dalam kartu pengolahan data (file data), (2) membuat tabel frekuensi atau tabel silang, (3) mengedit data. Teknis analisis statistik deskriptif yang digunakan dalam penelitian ini adalah melalui perhitungan mean atau rerata $(\mathrm{m})$ atau pengukuran tendensi sentral, median (me), dan modus (mo). Di samping itu untuk memaparkan data digunakan tabulasi dan visualisasinya dalam bentuk grafik.

\section{Hasil dan Pembahasan}

Berdasarkan pada beberapa fakta yang ditemukan dari hasil tracer study kepada alumni maupun user survey Poltekba maka sangatlah penting untuk mengetahui relevansi kompetensi lulusan Poltekba dengan model kompetensi lulusan yang dibutuhkan DUDI sehingga dapat menekan angka ketidaksesuaian (missmatch) kompetensi yang dimiliki lulusan Poltekba dengan kebutuhan DUDI. Salah satu temuan menarik hasil tracer study Poltekba adalah informasi tentang kualitas kompetensi lulusan Poltekba dan konstribusi institusi terhadap DUDI. Hal ini sangat berperan dalam peningkatan keselarasan kompetensi antara kompetensi yang diberikan 
oleh Poltekba dengan kompetensi yang dibutuhkan DUDI. Kompetensi yang diharapkan dari setiap lulusan pendidikan tinggi vokasi yakni memiliki dua sisi keahlian yakni hard skills dan soft skills.

Terdapat 4 aspek penting dalam kuesioner tracer study untuk melihat kompetensi lulusan yakni: masa tunggu mendapatkan pekerjaan, kesesuaian kompetensi dengan bidang pekerjaan, persebaran jenis pekerjaan alumni, dan kesesuaian jenjang pendidikan dengan kualifikasi pendidikan yang diminta oleh DUDI. Adapun penjabaran dalam tiap aspek dijelaskan pada Gambar1s.d Gambar 5.

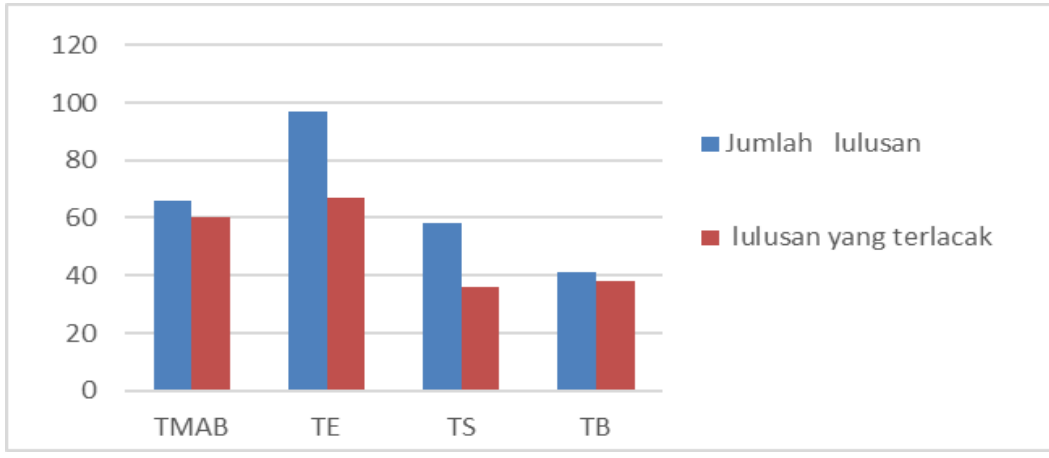

Gambar 1. Grafik Jumlah Lulusan yang Terlacak

Dari 262 lulusan Poltekba tahun 2019, 77\% alumni merespon ataupun terlacak untuk mengisi kuesioner tracer study sedangkan sisanya $23 \%$ lulusan tidak merespon dan tidak terlacak.

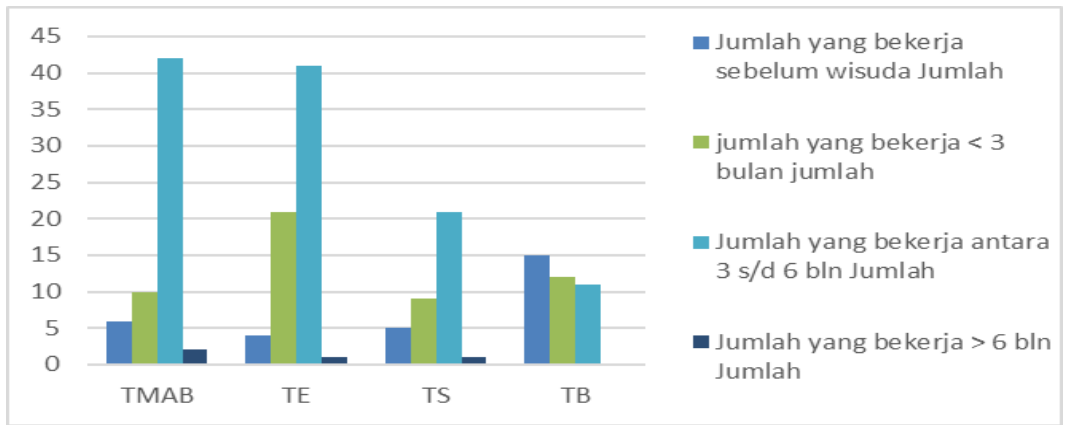

Gambar 2. Grafik Masa Tunggu Lulusan

Dari 201 lulusan yang terlacak , 15\% lulusan mendapat pekerjaan sebelum wisuda, $26 \%$ lulusan bekerja kurang dari 3 bulan, 57\% lulusan bekerja antara 3 s/d 6 bulan, dan sisanya $2 \%$ dengan waktu tunggu lebih dari 6 bulan setelah kelulusan untuk mendapat pekerjaan.

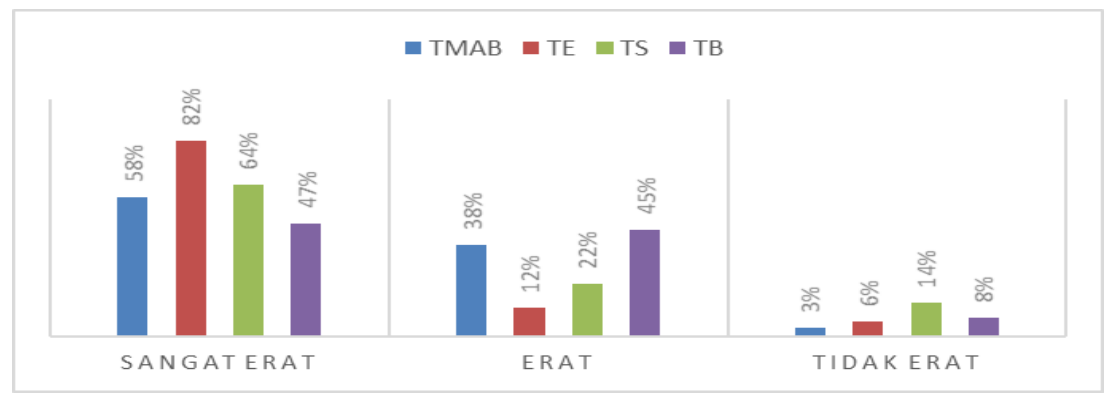

Gambar 3. Grafik Kesesuaian Kompetensi dengan Bidang Pekerjaan 
Dari 201 lulusan yang terlacak, 65\% lulusan menyatakan hubungan antara bidang studi (ilmu) pada saat kuliah sangat erat, $28 \%$ lulusan menyatakan hubungan antara bidang studi (ilmu) pada saat kuliah erat, dan 7\% lulusan menyatakan hubungan antara bidang studi (ilmu) pada saat kuliah tidak erat.

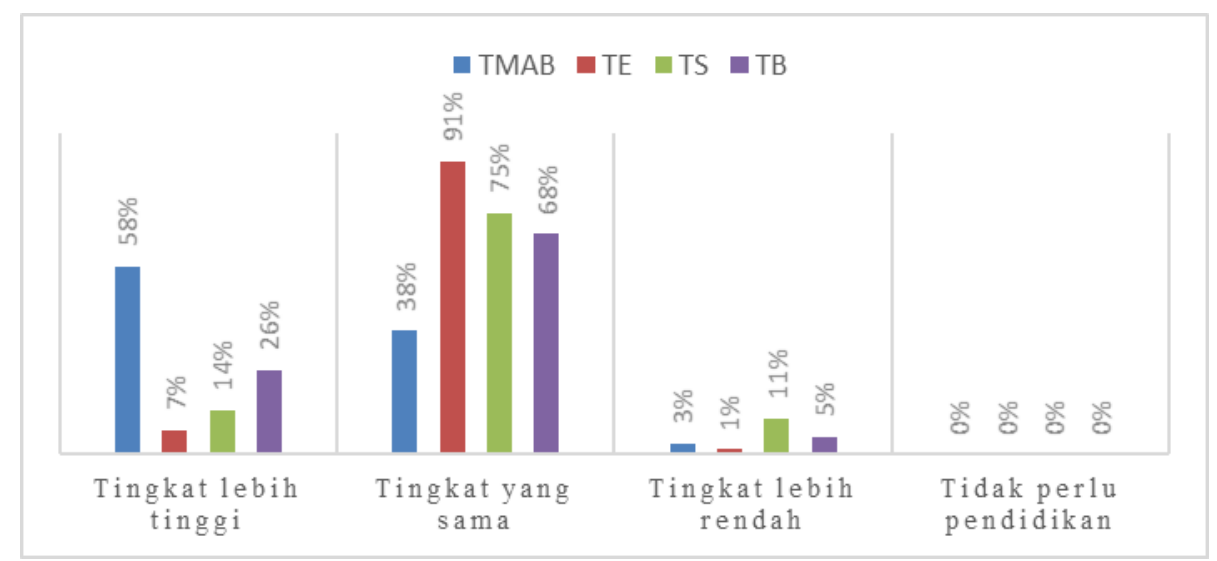

Gambar 4 . Grafik Kesuaian Tingkat Pendidikan dengan Kulifikasi Pekerjaan

Dari 201 lulusan yang terlacak, 27\% lulusan memiliki tingkat pendidikan setingkat lebih tinggi dengan pekerjaan lulusan, 68\% lulusan memiliki tingkat yang sama antara pendidikan dan pekerjaan, sedangkan $5 \%$ lulusan memiliki pekerjaan setingkat lebih rendah dari pendidikan lulusan.

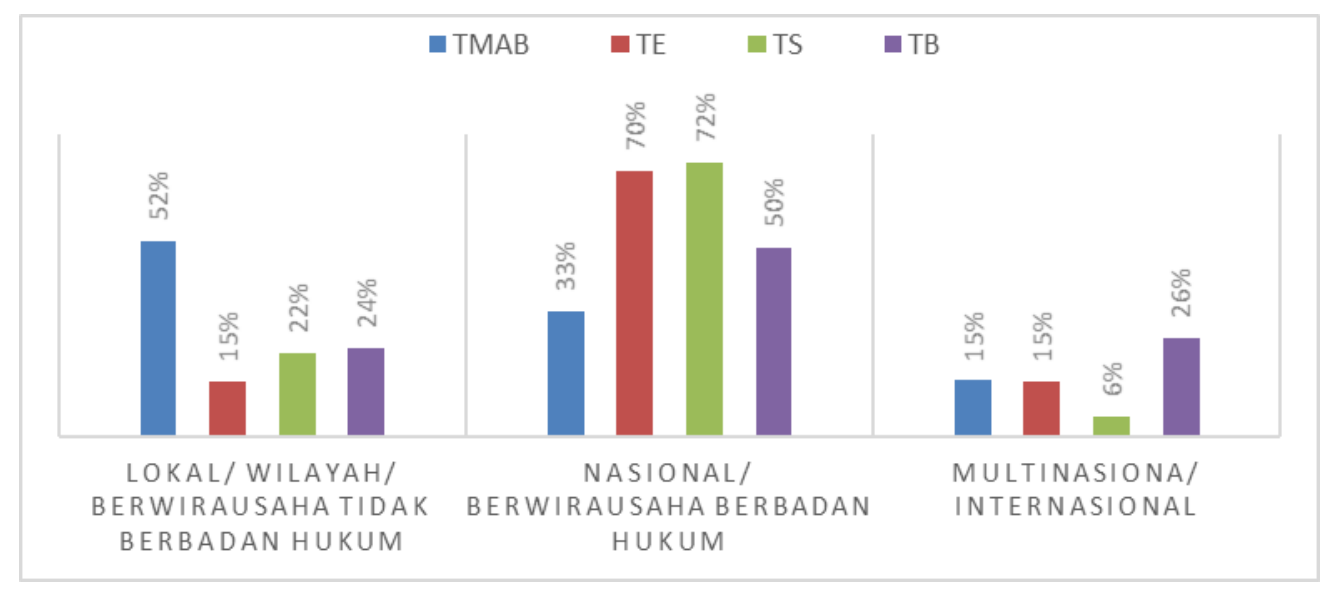

Gambar 5. Peta Persebaran Tempat Kerja Lulusan

Dari 201 lulusan yang terlacak, 29\% lulusan bekerja pada perusahaan lokal, 56\% lulusan bekerja pada perusahaan nasional, selebihnya $15 \%$ lulusan bekerja pada perusahaan multinasional.

Berdasarkan hasil user survey Poltekba dengan beberapa industri maka dapat disimpulkan bahwa dari 22 aspek model kompetensi yang dibutuhkan dalam dunia kerja yang meliputi 7 aspek hard skill yakni keahlian pendidikan, pengalaman kerja, sertifikasi keahlian, wawasan, komputer, penerapan ilmu kemampuan berbahasa asing dan 15 aspek soft skill yakni kepemimpinan, inisiatif, adaptasi, komunikasi, kerja keras, tanggung jawab, bekerja dalam tekanan, disiplin, bekerja tim, keinginan belajar, kejujuran, motivasi, etika, kecerdasan emosional dan loyalitas, maka dapat disimpulkan 7 aspek yang menjadi model kompetensi 
utama yang dibutuhkan oleh DUDI yang meliputi etika, keahlian pada bidang ilmu, kemampuan berbahasa asing, penggunaan teknologi informasi, kemampuan berkomunikasi, kerjasama, dan pengembangan diri.

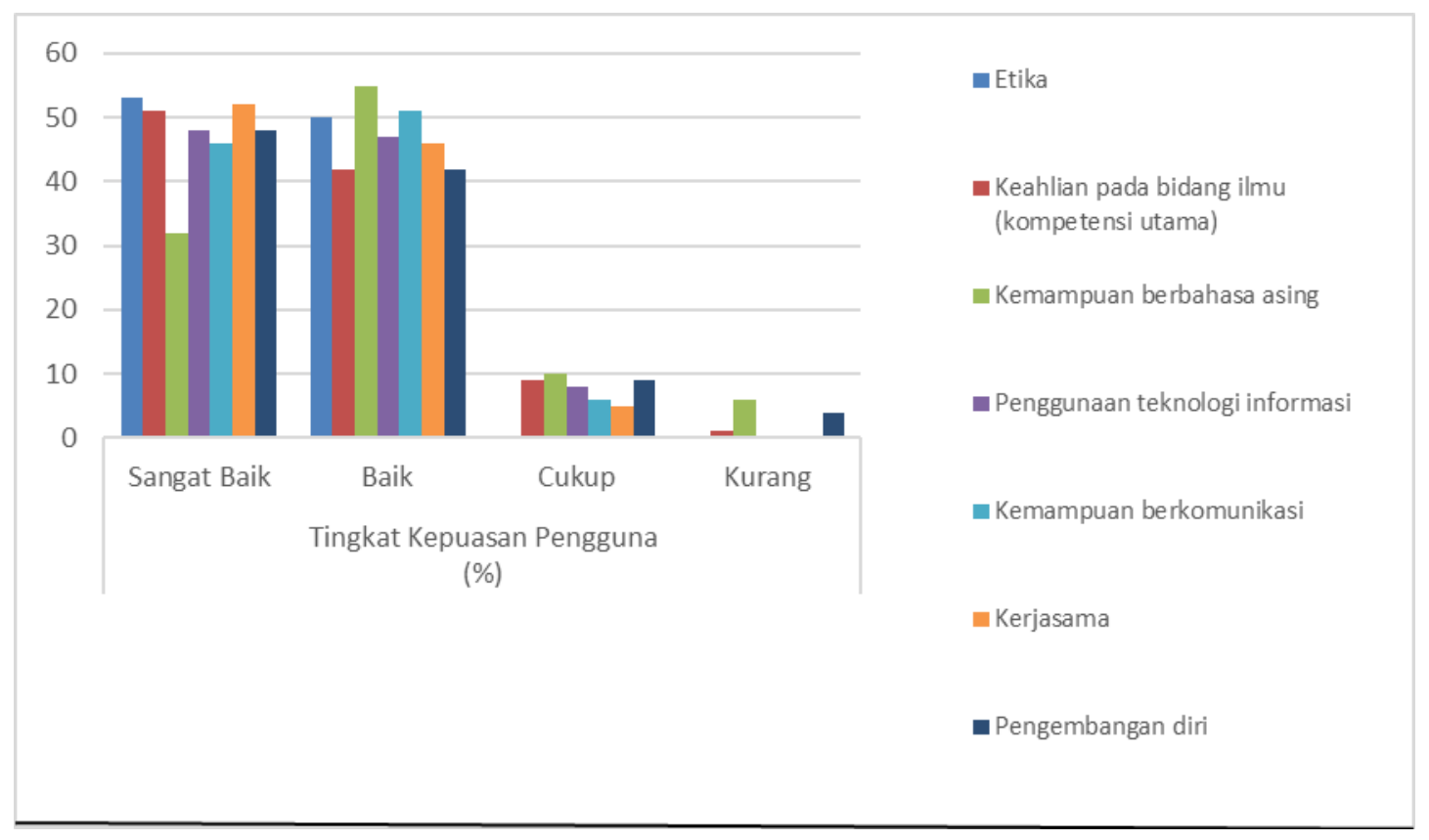

Gambar 6. Grafik Kepuasaan Pengguna Lulusan

Pada Gambar 6, dapat disimpulkan bahwa dari 7 aspek kompetensi berdasarkan tingkat kepuasan pengguna lulusan Poltekba terhadap aspek etika lulusan, terdapat 51,46\% menyatakan sangat baik, dan 48,54\% menyatakan baik. Untuk aspek keahlian pada bidang ilmu terlihat bahwa 49,51\% menyatakan sangat baik, 40,78\% menyatakan baik, 8,74\% menyatakan cukup, dan 0,97 menyatakan masih kurang. Sedangkan dalam kompetensi kemampuan berbahasa asing terdapat $31,06 \%$ pengguna lulusan yang menyatakan sangat baik, 53,40\% menyatakan baik, 9,71\% menyatakan cukup, dan 5,83\% menyatakan kurang. Dalam kemampuan penggunaan teknologi informasi terlihat bahawa 46,60\% menyatakan sangat baik, 45,63\% menyatakan baik, dan 7,77\% menyatakan cukup. Dalam aspek kemampuan berkomunikasi terdapat 44,67\% menyatakan sangat baik, 49,51\% menyatakan baik, 5,82\% menyatakan cukup. Untuk aspek kerjasama, terlihat bahwa 50,49\% pengguna lulusan menyatakan sangat baik, 44,66\% menyatakan baik, dan 4,85\% menyatakan cukup. Sedangkan dalam aspek pengembangan diri, terdapat46,60\% menyatakan sangat baik, 40,78\% menyatakan baik, 8,74 menyatakan cukup, dan 3,88 menyatakan kurang.

Berdasarkan analisa hasil tracer study terhadap lulusan Poltekba dan hasil analisa user survey terhadap pengguna lulusan maka dapat diidentifikasi analisa profil kompetensi lulusan Poltekba, model kompetensi utama DUDI dan relevansi antara kompetensi lulusan Poltekba dengan model kompetensi utama dari DUDI. Dilihat dari hasil tracer study maka dapat disimpulkan bahwa keselarasan vertikal yakni keselarasan tingkat pendidikan dan kebutuhan pekerjaan dinyatakan cukup tinggi dimana $68 \%$ lulusan memiliki tingkat yang sama antara pendidikan dan pekerjaan, sedangkan dilihat pada keselarasan horizontal yakni keselarasan bidang kompetensi studi lulusan dengan pekerjaan dinyataakan sangat erat dimana $65 \%$ lulusan menyatakan hubungan antara bidang studi (ilmu) pada saat kuliah sangat erat. Pada lulusan Poltekba tahun 2019 secara dominan memiliki masa tunggu mendapatkan pekerjaan antara $3 \mathrm{~s} / \mathrm{d}$ 6 bulan sebanyak $57 \%$ lulusan dan mayoritas bekerja pada perusahaan nasional atau berwirausah berbadan hukum. 
Sedangkan berdasarkan hasil user survey dimana dapat dismpulkan terdapat 7 kompetensi utama yang dibutuhkan DUDI yakni etika, keahlian pada bidang ilmu, kemampuan berbahasa asing, penggunaan teknologi informasi, kemampuan berkomunikasi, kerjasama, dan pengembangan diri, maka dapat disimpulkan bahwa masih terdapat beberapa apek kompetensi baik hard skill maupun soft skill yang perlu ditingkatkan agar tidak terjadi mismatch antara kebutuhan DUDI dengan output lulusan dari Poltekba. Masih terdapat 6 aspek yang dinyatakan cukup dan bahkan ada 3 aspek dinyatakan kurang yang dapat dikelompokan dalam kemampuan hardskill yakni keahlian pada bidang ilmu, kemampuan berbahasa asing, dan penggunaan teknologi informasi, sedangkan kemampuan soft skill yang meliputi kemampuan berkomunikasi, kerjasama, dan pengembangan diri.

Berdasarkan hasil analisa relevansi kompetensi lulusan Poltekba dengan kompetensi utama yang dibutuhkan DUDI maka dapat disimpulkan bahwa masih terjadi mismatch antara output lulusan Poltekba dengan model kompetensi utama yang dibutuhkan DUDI sehingga Poltekba perlu meningkatkan kualitas lulusan baik dalam aspek hard skill maupun aspek soft skill yang justru menjadi point penting ketika mereka menghadapi dunia kerja dimana harus memiliki life skill. Perlu adanya penyelarasan kurikulum agar kompetensi yang dihasilkan dapat lebih update sesuai dengan kebutuhan DUDI dan stimulus lebih dari institusi dalam mencetak lulusan yang memiliki hard skill yang mumpuni dan juga memilik karakter yang baik yang pastinya akan berpengaruh tehadap kualitas soft skill lulusan Poltekba. Dalam hal ini, sangat perlu ditekankan bahwa dalam dunia kerja tidak hanya mengedepankan hard skill saja namun juga soft skill yang kokoh dan berkarakter dalam memasuki dunia kerja sehingga diharapakan lulusan Poltekba selain dapat berkompetisi dengan lulusan dari perguruan tinggi vokasi lainnya dalam tes rekrutmen dari DUDI, tetapi juga dapat bertahan dan terus berkarya inovatif dalam dunia kerja nantinya.

\section{Kesimpulan}

Berdasarkan hasil analisa kuesioner tracer study alumni maupun user survey, dapat disimpulkan bahwa profil kompetensi lulusan Poltekba dapat bekerja sesuai dengan bidang kompetensi linier ilmunya sehingga hubungan antara jenis pekerjaan dengan bidang ilmu saat kuliah sangat erat dengan tingkat pendidikan yang sama dengan kualifikasi yang dibutuhkan oleh DUDI yakni diploma 3. Akan tetapi berdasarkan hasil evaluasi model kompetensi utama yang dibutuhkan DUDI terhadap kualitas lulusan Poltekba dapat disimpulkan bahwa masih terdapat beberapa aspek kompetensi yang masih perlu ditingkatkan dan diperlukan upaya dari institusi untuk dapat meningkatkan kualitas lulusan agar terwujud link and match antara insitusi Poltekba dengan DUDI dalam meningkatkan kompetensi lulusan agar sesuai dengan permintaan kebutuhan DUDI.

Dalam aspek hardskill masih terdapat beberapa kompetensi yang perlu ditingkatkan agar menghasilkan lulusan yang sesui dengan perkembangan teknologi yang dibutuhkan oleh pengguna lulusan diantaranya kompetensi penguasaan komputer, keahlian pada bidang ilmu (kompetensi utama), dan kemampuan berbicara dalam bahasa Inggris. Sedangkan dalam aspek soft skill masih diperlukan peningkatan pada kompetensi kemampuan berkomunikasi, kerja sama, dan pengembangan diri. Oleh karena itu sangat diperlukan dukungan yang kuat antara institusi, tenaga pendidik, maupun civitas akademika untuk dapat mendukung upaya dalam mencetak lulusan yang memiliki kemampuan hard skill dan soft skill yang siap dapat bersaing dalam dunia kerja dan terus berkembang sehingga tidak tergilas dengan adanya perkembangan kebuthan DUDI pada revolusi industry 4.0 ini. 


\section{Saran}

Berdarkan hasil penelitian ini, maka peneliti memiliki beberapa saran untuk dijadikan masukan yang relevan sebagai dasar pijakan pengembangan institusi untuk menangkap kesempatan dan menanggulangi ancaman ke depan, khususnya terhadap pembuat kebijakan pendidikan yakni:

1. Poltekba perlu meningkatkan kualitas softskill calon lulusan baik dalam kegiatan akademik maupun non akademik sehingga lulusan Poltekba tidak hanya mengedepankan hard skill saja tetapi juga soft skill yang justru menjadi bagian kriteria terpenting dalam memasuki dunia kerja dimana harus memiliki life skill.

2. Poltekba perlu meningkatkan hubungan link and match dengan DUDI sehingga kedepannya dapat meningkatkan hubungan mutualisme untuk perkembangan dunia pendidikan maupun DUDI.

3. DUDI (Dunia Usaha dan Industri) diharapkan dapat membuka kesempatan lebih dan peluang kerjasama dengan institusi pendidikan dalam berbagai bidang guna meningkatkan kualitas lulusan agar dapat sesuai dengan kebutuhan DUDI.

\section{Ucapan Terimakasih}

Penulis mengucapakan terima kasih pada P3M Politeknik Negeri Balikpapan atas support yang telah diberikan dalam penelitian ini, serta lulusan Poltekba maupun pengguna lulusan Poltekba (DUDI) yang telah berkenan untuk mengisi kuesioner tracer study dan user survey sehingga peneliti dapat mendapatkan data yang valid dan representative.

\section{Daftar Pustaka}

Boudarbat, B., \& Chernoff, V. (2015). The Determinants of Education-Job Match among Canadian University Graduates. IZA Discussion Paper, 43(6), 781-793.

Gaeta, G. L., Lavadera, G. L., \& Pastore, F. (2017). Much Ado about Nothing? The Wage Penalty of Holding a PhD Degree but Not a PhD Job Position. Research in Labor Economics, 10(1), 243-277.

Hersch, J. (2012). Education Match and Job Match. The Review of Economics and Statistics, 73(1), 650-664.

Masri Singarimbun dan Sofian Effendi. (1989). Metode Penelitian Survei. Jakarta: LP3ES.

Muhson dkk., (2012). Analisis Relevansi Lulusan Perguruan Tinggi dengan Dunia Kerja. Jurnal Economia Vol.8 No.1.

Nana, Sudjana. (2004). Penelitian dan Penilaian Pendidikan. Bandung: Sinar Baru Algesindo.

Prasetyono, Agus. (2017). Majalah Ristekdikti: Revitalisasi Pendidikan Tinggi Vokasi Vol.7 No.1. Jakarta: Ristekdikti.

Robst, J. (2017). Education and job match: The relatedness of college major and work. Economics of Education Review, 26, 397-407.

Senarath, S. A. C. L., \& Patabendige, S. S. J. (2014). Job-Education Mismatch Among the Graduates: A Sri Lankan Perspective. Ruhuna Journal of Management and Finance, l(2).

Sloane, P. J. (2013). Much Ado About Nothing? What Does The Over-Education Literature Really Tell Us?

Sugiyono. (2009). Metode Penelitian Kuantitatif, Kualitatif dan R\&D. Bandung: Alfabeta. 
WEF (World Economic Forum). (2018). The Global Competitiveness Report 2018. https://www.weforum.org/reports/the-global-competitveness-report-2018. Diakses tanggal 29 Maret 2020. 